\title{
Trabzon İlinde Gebelerde Hepatit B, Hepatit C, HIV ve RPR Seropozitifliği
}

\author{
Hepatitis B, Hepatitis C, HIV and RPR Seropositivity in Pregnants in Trabzon
}

\author{
Recep ERINN ${ }^{1}$, Deniz KULAKSIZ², Yeşim BAYOĞLU TEKINN ${ }^{3}$, Kübra BAKİ ERİN ${ }^{4}$
}

\section{ÖZ}

Gebelikte hepatit B, hepatit C, HIV ve sifiliz anneden bebeğe dikey ve yatay olarak bulaşabilir. Bu nedenle gebeler taranmalı ve saptanması halinde gerekli önlemler alınmalıdır. Trabzon İli ile ilgili ulusal ve uluslararası literatürde hepatit $\mathrm{B}$, hepatit $\mathrm{C}$, HIV ve sifiliz prevalansı ile ilgili bilgi bulunmamaktadır. Çalışmada amaç, Doğu Karadeniz Bölgesi'nin en büyük ili olan Trabzon'daki gebe popülasyonun Hepatit $\mathrm{B}$, hepatit $\mathrm{C}$, HIV ve sifiliz pozitifliğini araştırmaktır.

Çalışma retrospektif dosya araştırması şeklinde planlanmıştır. Ocak 2016-Aralık 2018 yılları arasında Kliniğimizde ayaktan ya da yatarak tedavi almış gebe kadınlar dahil edilmiştir. Dosya taramasından yaş, gravida, VKİ, gebelik haftası, özgeçmiş, HBsAg, anti HBs, anti HCV, anti HIV ve RPR pozitifliği elde edildi. Veriler SPSS ortamına aktarılarak yaş gruplarına göre ortalama değerler hesaplandı ve ki kare test uyguland.

Toplam 10449 gebe dosya bilgilerine ulaşıldı. Yaş ortalamasi $27,65 \pm 5,36$, BMI $26,9 \pm 4,23 \mathrm{~kg} / \mathrm{m}^{2}$, gravida $2,3 \pm 0,21$, gebelik haftas1 ortalama $24,12 \pm 3,54$ olarak tespit edildi. $\mathrm{HBsAg}+$ oran $1 \% 3,8$, anti $\mathrm{HBs}$ oran 1 $\% 49,5$, anti $\mathrm{HCV}+$ oran $1 \% 0,09$, RPR oran1 \%0,19, anti HIV oran $\% 0,09$, anti HIV pozitif çıkan gebelerin doğrulama testi pozitiflik oranı \%0,02 idi. Anti HBs pozitifliği 18-25 yaş aralığında \%75,9 olarak bulundu ve bu fark anlamliydı $(\mathrm{p}<0.05)$.

18-25 yaş grubunda anti HBs pozitifliği diğer yaş gruplarına göre anlamlı yüksek bulundu. Trabzon bölgesinde gebelerdeki seropozitiflik Türkiye literatürü ile benzerdir.

Anahtar Kelimeler: Anti HCV, Anti HIV, Gebe popülasyon, HBsAg, RPR

\section{ABSTRACT}

During pregnancy, hepatitis $\mathrm{B}$, hepatitis C, HIV and syphilis can be transmitted vertically and horizontally from mother to baby. Therefore, pregnant women should be screened and necessary measures should be taken if detected. There is no information about the prevalence of hepatitis B, hepatitis C, HIV and syphilis in the national and international literature about Trabzon Province. Our aim is to investigate the Hepatitis B, Hepatitis C, HIV and Syphilis positivity of the pregnant population in Trabzon, the largest city of the Eastern Black Sea Region.

The study was planned as a retrospective file research. Pregnant women who received outpatient or inpatient treatment in our clinic between January 2016 and December 2018 were included. Age, gravida, BMI, gestational week, history, HBsAg, anti HBs, anti HCV, anti HIV and RPR positivity were obtained from the file scan. The data were transferred to the SPSS environment, mean values were calculated according to age groups and a chi-square test was applied.

Files of 10449 pregnant women were reached. The mean age was $27.65 \pm 5.36$, BMI $26.9 \pm 4.23 \mathrm{~kg} / \mathrm{m}^{2}$, gravida was $2.3 \pm 0.21$, and the mean week of gestation was $24.12 \pm 3.54$. HBsAg + rate was $3.8 \%$, anti $\mathrm{HBs}$ rate $49.5 \%$, anti $\mathrm{HCV}+$ rate $0.09 \%$, RPR rate $0.19 \%$, anti HIV rate $0.09 \%$, and confirmation test positivity rate of pregnant women who were positive for anti HIV was $0.02 \%$. Anti HBs positivity was found to be $75.9 \%$ in the $18-25$ age range, and this difference was significant $(\mathrm{p}<0.05)$.

Anti HBs positivity was found to be significantly higher in the 18-25 age group compared to other age groups. seropositive pregnant women in Trabzon in Turkey is similar to literature.

Key words: Anti HCV, Anti HIV, Pregnant population, HBsAg, RPR

Sağllk Bilimleri Üniversitesi Trabzon Kanuni Sağlık Uygulama ve Araștırma Merkezi'nden idari izin (23618724-722.02) ve Etik Kuruldan 2019/30 numaralı izin alınmıştır.

${ }^{1}$ Dr. Öğr. Üyesi, Recep ERİN, Kadın Hastalıkları ve Doğum, SBÜ Trabzon SUAM, erinrecep@gmail.com, ORCID: 0000-0002-9488-5414 ${ }^{2}$ Dr. Öğr. Üyesi, Deniz KULAKSIZ, Kadın Hastalıkları ve Doğum, SBÜ Trabzon SUAM, drdenizkulaksiz@gmail.com, ORCID: 0000-00032351-1367

${ }^{3}$ Prof. Dr., Yeşim BAYOĞLU TEKİN, Kadın Hastalıkları ve Doğum, SBÜ Trabzon SUAM, yesimbay@yahoo.com, ORCID: 0000-00030865-3201,

${ }^{4}$ Dr. Öğr. Üyesi, Kübra BAKİ ERİN, Kadın Hastalıkları ve Doğum, SBÜ Trabzon SUAM, kubrabakierin@gmail.com, ORCID: 0000-00026626-1735

İletişim / Corresponding Author: $\quad$ Recep ERIN $\quad$ Geliş Tarihi / Received: 22.09 .2020

\begin{tabular}{llll} 
e-posta/e-mail: & erinrecep@gmail.com & Kabul Tarihi/Accepted: & 16.05 .2021 \\
\hline
\end{tabular}




\section{GİRIS}

Hepatit B, hepatit C, HIV (Human Immunodeficiency Virus) ve sifiliz enfeksiyonları global halk sağlığı problemleridir. Gebeler toplumun hassas bir popülasyonunu oluşturmaktadır. Gebelik tanısı konulduktan sonra hepatit $\mathrm{B}$, hepatit $\mathrm{C}$, HIV ve sifiliz RPR (rapid plazma reagin) seropozitifliğinin gebe bireylerde taranması önerilmektedir. ${ }^{1}$ Çünkü, bu enfeksiyonlar anneden bebeğe hem dikey hem de yatay olarak bulaşabilmektedir. ${ }^{2}$

Dünyadaki hepatit $\mathrm{B}$ sıklığı coğrafi bölgelere ve ülkelerin gelişmişlik düzeyine göre farklılıklar göstermektedir. Ülkelerin HBsAg prevalansina durumuna göre sınıflandırma yapılmaktadır. Buna göre \%2 altında taşıyıcılık düşük, \%2-10 arası orta, $\% 10$ 'dan fazla olanlar ise yüksek endemik bölge olarak kabul edilmektedir. $\mathrm{Bu}$ sınıflamada Türkiye mevcut literatür bilgisi dahilinde orta taşıyıcılık bölgesindedir. ${ }^{3}$ Türkiye'deki hepatit B sıklığı ile ilgili veriler illere göre değișiklik göstermekle beraber $\%$ 1,2-19,2 arasında olduğunu bildiren çalışmalar vardır. ${ }^{4}$

Dünyada Hepatit C ile enfekte yaklaşık 170 milyon insan olduğu düşünülmektedir ve kronik hepatit enfeksiyonlarının \%70'nden hepatit C sorumludur. ${ }^{5}$ Dünyada 2019 y1lı itibariyle 38 milyon insan HIV ile enfektedir. $^{6}$

Trabzon ili ile ilgili ulusal ve uluslararası literatürde hepatit $\mathrm{B}$, hepatit $\mathrm{C}$, HIV ve sfiliz prevalansı ile ilgili bilgi bulunmamaktadır. Çalışmada amaç, Doğu Karadeniz Bölgesi'nin en büyük ili olan Trabzon'daki gebe popülasyonunda Hepatit $B$, hepatit $C$, HIV ve sifiliz pozitifliğini araştırmaktır.

\section{MATERYAL VE METOT}

\section{Verilerin Toplanması}

Çalışma retrospektif dosya araştırması şeklinde planlanmıştır. Ocak 2016 - Aralık 2018 yılları arasında Trabzon Kanuni Sağlık Uygulama ve Araştırma Merkezi Kadın Hastalıkları ve Doğum Kliniğinde ayaktan ya da yatarak tedavi edilmiş gebe kadınlar dahil edilmiştir.

Trabzon'un hatta Doğu Karadeniz Bölgesi'nin tüm kırsal ve kentsel yerleşimlerinden gebeler hastanemize başvurmaktadır. Dosya taramasından yaş, gravida, parite, VKİ (vücut kitle indeksi), gebelik haftas1, fetüs sayısı, özgeçmiş, soygeçmiş bilgisi, doğum şekli, HBsAg, anti HBs, anti HCV, anti HIV ve VDRL pozitifliği elde edilmişstir.

Eliza testi için sarı biyokimta tüpüne antekübital venden elde edilmiş kan örneği ve serumu kullanılmıştır. Eliza testi için HBsAg Qual II (Abbott Architect, Illionis, USA), anti-HBs II (Abbott Architect, Illionis, USA) anti HIV (Abbott Architect, Illionis, USA) ve anti-HCV II (Abbott Architect, Illionis, USA) kitleri kullanılmıştır. Sifiliz taraması için immutrep RPR (Omega, Cambridgeshire, United Kingdom) kullanılmıştır. HBsAg, AntiHCV ve antiHIV için cut off değeri $>1$, antiHBs için cutoff index $>10 \mathrm{IU} / \mathrm{mL}$ alınmıștır.

İstatiksel analiz için tüm verilerin (version 23.0, Armonk, NY, USA) ortamina aktarılması planlanmıştır. Verilerin frekans ve ortalama değerleri hesaplanmıștır. Yaş gruplarına göre anlamlılık için ki kare testi uygulanmıştır. Anlamlılık için $\mathrm{P}<0.05$ anlamlı kabul edilmiştir.

\section{Araştırmanın Etik Yönü}

Sağlı Bilimleri Üniversitesi Trabzon Kanuni Sağlık Uygulama ve Araştırma Merkezi'nden idari izin (23618724-722.02) ve Etik Kurul' dan yerel etik kurul onay1 (2019/30) alınmıştır.

\section{Araștırmanın Kısıtlılıkları}

Çalışmanın önemli bir kısıtlılığı retrospektif olmasıdır. Ayrıca örneklemiz toplumun tüm fertlerini değil gebe popülasyonu yansitmaktadır. Dosya taramasında eksik, yanlış ya da özensiz dosya 
bilgileri olan olgular çalışmadan çıkartılmıştır. Hastanemiz, Doğu Karadeniz Bölgesi'nin en büyük ve referans Merkezi olmasına rağmen hastane verileri tüm bölgeyi yansıtmayabilir. Tüm bölgeyi yansitacak veriler için bölgesinin tüm illerinin katıldı ğ araştırmalarla çalışma desteklenmelidir.

\section{Çıkar Çatışması}

Yazarlar çıkar çatışması olmadığını beyan ederler.

\section{BULGULAR VE TARTIŞMA}

3 yıllık dosya analizinde toplam 10449 gebenin dosya bilgilerine ulaşılmıştır. Demografik verilerin analizinde; yaş ortalamas1 $27,65 \pm 5,36, \quad$ BMI $26,9 \pm 4,23$ $\mathrm{kg} / \mathrm{m}^{2}$, gravida $2,3 \pm 0,21$, gebelik haftas 1 ortalama $24,12 \pm 3,54$ olarak tespit edilmiştir.

HBsAg + oran $1 \% 3,8$, anti HBs oran 1 $\% 49,5$, anti $\mathrm{HCV}+$ oran $1 \% 0,09$, sifiliz oran 1
$\% 0,19$, anti HIV oran1 \%0,09, anti HIV pozitif çıkan gebelerin doğrulama testi pozitiflik oran $1 \% 0,02$ idi.

Yaş grubuna göre dağılım tabloda verilmiştir (Tablo 1). Anti HBs pozitifliği 1825 yaş aralığında \%75,9 olarak bulundu ve bu farkın istatiksel olarak anlamlı olduğu tespit edilmiştir $(\mathrm{p}<0,05)$.

Tablo 1. Yaş Aralığına Göre HBsAg, Anti HBs, Anti HCV, Anti HIV ve RPR Pozitiflik Oranlarının Dağılımı

\begin{tabular}{rrrrrrrr}
\hline Yaş aralığı & Sayı/yüzde & $\begin{array}{l}\text { HBsAg } \\
\text { pozitif n(\%) }\end{array}$ & $\begin{array}{l}\text { Anti } \\
\text { pozitif } \mathbf{n}(\%)\end{array}$ & $\begin{array}{l}\text { HCV } \mathbf{n}(\%) \\
\text { pozitif }\end{array}$ & $\begin{array}{l}\text { Anti } \\
\text { pozitif n(\%) }\end{array}$ & $\begin{array}{l}\text { RPR }(\%) \\
\mathbf{n}(\%)\end{array}$ & pozitif \\
\hline $\mathbf{1 8 - 2 5}$ & $3797(36,3)$ & $73(1,9)$ & $2881(75,9)$ & $2(0,05)$ & $2(0,05)$ & $5(0,13)$ \\
\hline $\mathbf{2 6 - 3 0}$ & $3053(29,2)$ & $154(4,9)$ & $1321(43,3)$ & $3(0,09)$ & $3(0,09)$ & $4(0,13)$ \\
\hline $\mathbf{3 1 - 3 5}$ & $2109(20,3)$ & $115(5,4)$ & $636(30,2)$ & $2(0,09)$ & $3(0,14)$ & $6(0,28)$ \\
\hline $\mathbf{3 6 - 4 0}$ & $1353(12,9)$ & $49(3,6)$ & $319(23,6)$ & $2(0,14)$ & $1(0,74)$ & $4(0,29)$ \\
\hline$>40$ & $137(1,3)$ & $9(6,5)$ & $20(14,5)$ & $1(0,72)$ & $1(0,72)$ & $1(0,72)$ \\
\hline Toplam & $10449(100)$ & $400(3,8)$ & $5177(49,5)$ & $10(0,09)$ & $10(0,09)$ & $20(0,19)$
\end{tabular}

HBsAg: Hepatitis B surface antigen, HCV: Hepatitis C virus, HBs: Hepatitis B surface, RPR: rapid plazma reagin, n:sayl, \%:yüzde

Hepatit B, enfekte bir anneden bebeğe dikey geçebilen ve tedavisi bulunan bir enfeksiyon hastalığıdır. HBs Ag pozitif annelerde neonatal enfeksiyon oranının \%1020 olduğunu bildiren çalışmalar vardır. ${ }^{7}$ Tedavisi bulunduğu için gebelikte taranması, fetusun korunması için önem arz etmektedir.

Bebeği korumak amaciyla doğumdan sonra aşılama ve immünoglobulin uygulaması yapılmaktadır. Yine ciddi hastalık bulguları bulunan yüksek viremiye sahip gebelere son trimesterde antiviral tedavi başlanarak fetüs korunabilir. ${ }^{8}$ Tüm bu sebeplerden ötürü hepatit B seropozitifliğinin gebelikte taranması önerilmektedir. ${ }^{9}$

Türkiye'deki gebelerdeki hepatit B pozitifliği ile ilgili prevalans verilerine baktığımızda en kapsamlı çalışmayı Bakar ve arkadaşları tarafindan 2016 yılında yapılmıştır. 4037 gebenin incelendiği çalışmada gebelerde HBsAg seropozitiflik sıklığını $\% 2,16$ olarak bulmuşlardır. ${ }^{4}$ 
Tablo 2. Gebelerde Son Yıllarda Yapılmış HBsAg, Anti HBs, Anti HCV, Anti HIV ve RPR Pozitiflik Oranları

\begin{tabular}{llllllll}
\hline Yazar & Yll & Bölge & HBsAg & Anti HBs & Anti HCV & Anti HIV & RPR \\
pozitif $(\%)$ & pozitif $(\%)$ & pozitif (\%) & $\begin{array}{l}\text { pozitif } \\
(\%)\end{array}$ & $\begin{array}{l}\text { pozitif } \\
(\%)\end{array}$
\end{tabular}

\begin{tabular}{|c|c|c|c|c|c|c|c|}
\hline Bakar vd. ${ }^{4}$ & 2016 & İstanbul & $4037(2,13)$ & - & - & - & - \\
\hline Yılmazer vd.10 & 2004 & Afyon & $7(2,9)$ & $45(18,4)$ & 0 & - & - \\
\hline Kasap vd. ${ }^{18}$ & 2017 & Muğla & $5(1,8)$ & $78(23,7)$ & $1(0,3)$ & 0 & - \\
\hline Dündar vd. ${ }^{19}$ & 2009 & İstanbul & $78(2,2)$ & $568(16,2)$ & $2(0,1)$ & 0 & - \\
\hline Biri vd. ${ }^{20}$ & 2001 & Ankara & $31(7)$ & - & $3(0,8)$ & $1(0,2)$ & - \\
\hline Doğan vd. ${ }^{21}$ & 2014 & İstanbul & $18(1,2)$ & $366(26,3)$ & - & - & 0 \\
\hline Çiçek vd. ${ }^{22}$ & 2012 & Şanlıurfa & $1968(3,5)$ & $3436(25)$ & $106(0,8)$ & - & - \\
\hline Şahin vd. ${ }^{8}$ & 2018 & Şırnak & $22(1)$ & $381(27,8)$ & $3(0,21)$ & - & - \\
\hline Dağlı vd ${ }^{17}$ & 2017 & Kurşehir & $11(1,3)$ & $297(35,7)$ & 0 & 0 & - \\
\hline Erin vd.* & 2020 & Trabzon & $400(3,8)$ & $5177(49,5)$ & $10(0,09)$ & $10(0,09)$ & $20(0,19)$ \\
\hline
\end{tabular}

HBsAg: Hepatitis B surface antigen, HCV: Hepatitis C virus, HBs: Hepatitis B surface, RPR: rapid plazma reagin, \%:yüzde

Ülkemizde gebelerde Hepatit B prevalansının değerlendirildiği toplam 64 çalı̧̧ma bulunmaktadır ve yayınlanan bu çalı̧̧malarda Türkiye'deki gebelerde HBsAg seropozitiflik oranının \%1,2-19,2 arasında olduğunu bildirmişlerdir (Tablo 2).

Son 20 yılda yapılan çalıșmalar incelendiğinde en yüksek oranın $\% 9,3$ olduğu, yurt genelinde uygulanan aşılama programının da etkisiyle son 7 yılda yapılan çalışmalarda \%6'nın üzerinde bir HBsAg seropozitifliğine rastlanmadığı görülmüștür. ${ }^{4}$

Anti HBs pozitiflik çalışmalarında 2000'li yillarda anti HBs pozitiflik oranının \%18 civarı olduğu görülmektedir. ${ }^{10} \mathrm{Bu}$ oran zamanla artmış ve en son bu çalışmada \%49'lara ulaşmıştır. Çalışmada, diğer çalışmalara benzer olarak gebelerde $\mathrm{HBsAg}$ seropozitifliğini $\% 3,8$ olarak bulunmuştur.

Çalışmada 18-25 yaş grubunda diğer yaş gruplarına göre anlaml bir anti HBs pozitiflik oranı saptanmıştır. Tüm bu oranlardaki değişimlerin en büyük nedeni

Ayrıca bu çalışmada antiHBs seropozitifliği bakılmamıştır.
Hepatit B'nin, Türkiye de 1998 yılından itibaren aşılama programına alınmasıdır. ${ }^{11}$

Kliniğimiz, Doğu Karadeniz Bölgesi'nin referans hastanesi olma özelliğindedir. Trabzon ilinde lokalize olan hastanemiz Giresun, Rize, Artvin, Gümüşhane ve Bayburt illerini de kapsayan yaklaşık 1,5 milyon popülasyona hizmet vermektedir.

Çalışma Doğu Karadeniz Bölgesi'ndeki gebelerde hepatit B prevalansı ile ilgili ilk yayın olma özelliğindedir. Bölgemizde hepatit B prevalansı ile ilgili yapılan benzer çalışmalar kan donörlerinde bakılan prevalansla ilgilidir. Bunula ilgili Kaya S.'nin 2008 yllında 12092 kan donöründe yaptı̆̆ çalışmada HBsAg seropozitifliği örneklerin \%1,6'sında, anti-HCV \%0,2'sinde, RPR pozitifliği $\% 0,001$ 'inde saptanmıştır, anti-HIV1/2 seropozitifliği hiçbir örnekte saptanmamıştır. ${ }^{5}$ Çalışma kan dönorlerini içerdiği için katılımcıların çoğunluğu erkek $(\% 97,5)$ popülasyondan oluşmaktaydı. Kadın popülasyona yönelik sağlıklı veri sağlayacak yeterince örneklem bulunmamaktaydı.

Çalışmada gebe kadınlarda HBsAg+ oranı $\% 3,8$, anti HBs oran1 $\% 49,5$, anti HCV + oran1 $\% 0,09$, RPR oran $1 \% 0,19$, anti HIV 
oran $\% 0,09$, anti HIV pozitif çıkan gebelerin doğrulama testi pozitiflik oran $1 \% 0,02$ 'ydi.

Çalışma, bölgenin anti HBS pozitiflik oranının saptandığı ilk çalışma olma özelliğindedir ve gebe popülasyonunun yaklaşık yarısında Hepatit B 'ye doğal ya da kazanılmış bağışıklık bulunduğu tespit edilmiştir.

Ülkemizdeki HCV seropozitifliğini \%0,11,1 aralığında bildiren çalışmalar vardır. ${ }^{12,13}$ En sık bulaş yolu parenteral temastır. Bu çalışmada gebelerdeki oran \%0,09 bulunmuştur. Hepatit B enfeksiyonunun aksine HCV enfeksiyonunun dikey geçişini azaltmak veya önlemek için kanıtlanmış bir aşı, müdahale veya onaylanmış tedavi modern tıp imkanlarına rağmen hala bulunmamaktadır. $\mathrm{Bu}$ nedenlerden ötürü rutin prenatal HCV taramas1 önerilmemektedir. Ancak maternal intravenöz ilaç bağımlılığı, HIV enfeksiyonu gibi risk grubunda olan gebelere hepatit $\mathrm{C}$ taraması önerilmektedir. ${ }^{14}$
Türkiye'de ilk kazanılmış immün yetmezlik sendromu (AIDS) vakas1 1985 yılında görülmüştür. 2019 yılı itibariyle toplam 3944 HIV/AIDS vakası (3813 HIV pozitif; 131 AIDS) bildirilmiştir. 0 yaş grubunda 92 vaka bildirilmiştir. Bu oranlar anneden bebeğe geçişin önemini göstermektedir. ${ }^{15}$ HIV pozitif anneden bebeğe geçişi önlemek için; gebeye antiretroviral tedavi başlanması ve düzenli doktor kontrolünde olma, doğumun elektif şartlarda 38. haftada sezaryen ile planlanmas1, bebeğe doğum sonrası antiretroviral profilaksi başlanması ve anne sütü verilmemesi say1labilir. ${ }^{16}$

Hepatit B aşılama programı sayesinde 1825 yaş grubunda anti HBs pozitifliği diğer yaşlara göre anlamlı yüksek bulunmuştur. Anneden bebeğe dikey ve yatay geçiş yapabilen hepatit $B$, hepatit C, HIV ve sifilisin gebelikteki önemi ve görülme oranları çalışma sayesinde vurgulanmıştır.

\section{SONUÇ VE ÖNERILLER}

Sonuç olarak, hepatit B aşılama programı sayesinde 18-25 yaş grubunda anti HBs pozitifliği diğer yaşlara göre anlamlı yüksek bulunmuştur. Anneden bebeğe dikey ve yatay geçiş yapabilen hepatit $\mathrm{B}$, hepatit $\mathrm{C}$, HIV ve sifilisin gebelikteki önemi çalışma ile vurgulanmıştır. Hepatit $\mathrm{B}$ virüsünün tedavisi olduğundan gebelikte taranmasinı öneriyoruz. Ancak yakın 10-20 yılda aşılama sayesinde Türkiye'den tamamen ortadan kalkacağını düşünüyoruz. Bu çalışma ile, Doğu Karadeniz Bölgesi'nin en büyük ili olan Trabzon'daki gebelerde prevalans bildirilerek literatüre katkı sağlanmıştır.

\section{KAYNAKLAR}

1. Nelson, P.N, Jamieson, D.J. and Murphy, T.V. (2014) "Prevention of Perinatal Hepatitis B Virus Transmission". J Pediatric Infect Dis Soc, 3, 7-12. doi: 10.1093/jpids/piu064

2. Giaquinto, C, Ruga, E, Gacomet, V, Rampon, O, D'Elia, R. (1998). "HIV: mother to child transmission, current knowledge and on-going studies". Int J Gynaecol Obstet, 63, 5161-5165. doi: 10.1016/s0020-7292(98)00200-8

3. Dilek, İ, Demir, C, Bay, A, et al. (2007). "Seropositivity rates of $\mathrm{HBsAg}$, anti-HCV, anti-HIV and VDRL in blood donors in Eastern Turkey". Turk J Hematol, 24 (1), 4-7.

4. Bakar, B.Z. ve Dane, B. (2016). "Gebelerde hepatit B seropozitifliği ve Türk literatürüne bir bakış". Perinatal Journal, 24 (2), 83-88. doi:10.2399/prn.16.0242005

5. Kaya, S. (2008). "Kan Donörlerinde Hepatit B Virusu, Hepatit C Virusu ve insan immün yetmezlik virusu enfeksiyonu ve sifilis sıklığı”. Klimik Dergisi, 21 (2), 65 68.
6. WHO. (2020). HIV-AIDS. https://www.who.int/healthtopics/hiv-aids. Erişim tarihi 11.09.2020.

7. Malatyalıoğlu, E. (2001). "Perinatal Enfeksiyonlar". (Editörler) Beksaç MS, Demir N, Koç A, Yüksel A. Obstetrik Maternal Fetal Tip \& Perinatoloji. (s.470-523). Ankara. MN Medikal \& Nobel.

8. Şahin, M, Zencir, M, Gözübüyük, A.A. and Pektaş, B.A (2018). "Seroprevalence of Hepatitis B Surface Antigen, Anti-Hepatitis B Surface and Anti-Hepatitis C Virus Among Pregnant Women Residing in Şırnak Province". Viral Hepatitis Journal, 24 (1), 7-11. doi: 10.4274/vhd.00 10

9. Balık, G, Üstüner, I, Kağıtcı, M, Ural, Ü.M, Tekin, Y.B. ve Şentürk, Ş. et al. (2013). "Rize bölgesinde yaşayan gebe kadınlarda HBsAg, AntiHBs ve Anti-HCV seroprevalansı". Dicle Trp Dergisi, 40, 254-257. doi: 10.5798/diclemedj. 0921.2013.02.0265 
10. Yılmazer, M, Altındiş, M, Sevrioğlu, S, Fenkci, S, Aktepe, O. and Sirthan, E. (2004). "Toxoplasma, Cytomegalovirus, Rubella, Hepatitis B and Hepatitis C Seropositivity Rates in Pregnant Women Who Live in Afyon Region”. The Medical Journal of Kocatepe, 5, 49-53.

11. Baykam, N, Güner, R. (2018). "Epidemiology of Viral Hepatitis Changes in Our Country". Viral Hepatitis Journal, 24 (1), 1-2. Doi: 10.4274/vhd.2018.1.0001

12. Pasha, A, Erdemoğlu, A.G, Özsoy, M.F, et al. (1999) "Seroprevalance of HBV and HCV in Health Workers". IX. Congress of Turkish Clinical Microbiology and Infectious Disease.

13. Mistik, R. ve Balık, İ. (2000). "Türkiye'de viral hepatitlerin epidemiyolojik analizi". Viral Hepatit, 36. VHSD, Istanbul.

14. Kuncio, D.E, Newbern, E.C, Johnson, C.C. and Viner, K.M. (2016). "Failure to Test and Identify Perinatally Infected Children Born to Hepatitis C Virus-Infected Women”. Clin Infect Dis. 62, 980-985. doi.org/10.1093/ $\mathrm{cid} / \mathrm{ciw} 026$

15. https://hsgm.saglik.gov.tr/tr/bulasici-hastaliklar/hiv-aids/ hiv-aids-liste/hiv-aids-istatislik.html. Erişim tarihi 12.09 2020

16. Sütçü, M. ve Somer, A. (2014). “Anneden Bebeğe HIV Geçişinin Önlenmesi”. Çocuk Dergisi 14 (4), 138-142. doi:10.5222/j.child.2014.138

17. Dağll, S.S and Demir, T. (2018). "The Prevalance of HBsAg, Anti-HBs, Anti-HCV AND Anti-HIV AM Among Women Admitted to Gynecology And Obstetrics Hospital In Kirsehir Province". Ahi Evran Med J, 1, 1-4.

18. Kasap, B, Öner, G, Küçük, M, Turhan, N.Ö, Akın, M.N, Arıkan, S, et al. (2017). "Evaluation of toxoplasmosis, rubella, cytomegalovirus and hepatitis prevalence of pregnant women in Muğla”. TıpTepecik Eğit. ve Araşt. Hast. Dergisi, 27 (1), 31-36.

19. Dündar, Ö, Çelik, S, Tütüncü, L, Ergür, A.R, Atay, V. ve Müngen, E. (2009). "2000-2005 Yilları Arasında Kliniğimizde Doğum Yapan Gebelerde Hepatit B, B, HIV, Toxoplazma, Rubella Prevalansının Araştırılması”. Zeynep Kamil Tıp Bülteni. 40, 1.

20. Biri, A, Kılıc, G, Bozdayı, G. and Tezcan, S. (2001) "Prevalence of Hepatitis B, Hepatitis C and Human Immunodeficiency Viruses During Pregnancy". T Klin J Med Res, 19, 100-103.

21. Doğan, K, Guraslan, H, Ozel, G, Aydan, Z and Yașar, L. (2014). "Seroprevalence Rates of Toxoplasma gondii, Rubella, Cytomegalovirus, Syphilis, and Hepatitis B, Seroprevalences Rate in The Pregnant Population in İstanbul". Turkiye Parazitol Derg, 38, 228-33. doi: $10.5152 /$ tpd.2014.3435

22. Çiçek, A.Ç, Duygu, F. and İnakçı, İ.H. (2012). "Hepatitis B and Hepatitis C Seropositivities in Women Admitted To Gynecology and Obstetrics Hospital in Şanlıurfa City: A 3Year Evaluation". Viral Hepatitis Journal, 18 (1), 15-18. doi: 10.4274/Vhd.18.04. 